\title{
Prospective comparison of laser nephelometry with standard agglutination techniques for detection of rheumatoid factor
}

\author{
A G PRENTICE, * P HICKLING, $\dagger$ I C WISEMAN, ${ }^{*}$ C J HOLWILL, * J NORTHWOOD \\ From the Departments of $\nmid$ Rheumatology, ${ }^{*}$ Haematology, and $\ddagger$ Microbiology, Derriford Hospital, Plymouth, \\ Devon
}

SUMMARY IgM rheumatoid factor was assayed by three routine methods: latex fixation; haemagglutination; and end point laser nephelometry in 69 patients with definite or classical rheumatoid arthritis and 58 patients with other non-rheumatoid arthropathies, selected prospectively according to the American Rheumatism Association clinical criteria. The operators of the assays were unaware of the clinical diagnoses. In the group with rheumatoid arthritis $75.4 \%$ were positive by latex fixation, $73.9 \%$ by haemagglutination, and $55.1 \%$ by nephelometry. In the group with nonrheumatoid arthropathies $10.4 \%$ were positive by latex fixation, $8.6 \%$ by haemagglutination, and $10.4 \%$ by nephelometry. Thus the simple and inexpensive latex fixation test was as good as the haemagglutination test, and both were significantly better than nephelometry in the laboratory confirmation of the clinical diagnosis of definite or classic rheumatoid arthritis $\left(\chi^{2}=5.40\right.$ and 4.56 , and $p<0.025$ and $<0.05$, respectively). None of these tests was significantly better or worse than the others in producing positive results in the group with non-rheumatoid arthropathies.

The diagnosis of rheumatoid arthritis is largely based on clinical evidence and depends on the fulfilment of the criteria for definite or classic disease, as described by Ropes et al. ${ }^{1}$ There are several laboratory methods of assay for IgM rheumatoid factor in serum, however, which may be used to confirm the clinical diagnosis. Until recently all these methods depended on the same principle of agglutination by serum IgM rheumatoid factor of particles coated with gammaglobulin. The differential sheep red cell agglutination test described by $\operatorname{Rose}^{2}(R-W$ test) has been in use for nearly 40 years, the latex fixation test ${ }^{3}$ for 30 years, and the haemagglutination test ${ }^{4}$ for 20 years. The variable and inadequate specificity and sensitivity of these variations on the same technique are well known. ${ }^{56}$

Laser nephelometry has begun to be used more in the routine measurement of plasma proteins, including IgM rheumatoid factor. ${ }^{78}$ This technique depends on the formation of antigen-antibody

Accepted for publication 21 August 1986 complexes, which scatter a beam of light in proportion to the concentration of the antibody in the test serum. Several studies on the detection of serum IgM rheumatoid factor have now been published, in which it is claimed that laser nephelometry may be equal or superior to the older agglutination techniques in several respects, including sensitivity and specificity. ${ }^{9-12}$ As the clinical context of these studies is not always clear, however, we conducted a prospective comparative study of laser nephelometry $v$ two agglutination techniques (latex fixation and haemagglutination) to detect IgM rheumatoid factor in patients who had been selected prospectively on clinical grounds only and not on the basis of previous serological results where these were available.

\section{Material and methods}

Sera were obtained from 69 patients with definite or classic rheumatoid arthritis and 58 patients with nonrheumatoid arthropathy or soft tissue rheumatism. The study was prospective, and any previous serological results were not considered when the patients were selected. The clinical diagnosis was unknown to 
the operators of the assays. All sera were stored at $-20^{\circ} \mathrm{C}$ and thawed before assay at room temperature. All reagents used were of analytical grade.

\section{LATEX FIXATION TEST}

This test was carried out with the Rheuma Wellcotest kit (Wellcome Reagents Ltd, Wellcome Research Laboratories, Beckenham, Kent, England). Macroscopic agglutination of IgG coated latex particles indicated a positive reaction. Quantitation of positive results was not done. Positive and negative controls were included.

\section{HAEMAGGLUTINATION TEST}

This test was carried out with the Fujozoki kit (Diamed Diagnostics Ltd, Bootle, Merseyside, England) in which fixed sheep red cells are coated with denatured rabbit IgG. The assays were done in the microtitre plates provided. Patients' sera were heated at $56^{\circ} \mathrm{C}$ for 30 minutes to inactivate complement. A range of dilutions from $1 / 20$ to $1 / 320$ were prepared in the absorbing diluent supplied by the manufacturers. A duplicate well of 1/20 dilution served as a negative control.

Dilutions were allowed to stand at room temperature for 30 minutes for the absorption of nonspecific effects. Reconstituted sensitised (test) cells $(25 \mu \mathrm{l})$ were added to each of the test dilutions and $25 \mu \mathrm{l}$ of unsensitised (control) cells were added to the control well containing the duplicate $1 / 20$ dilution. Positive and negative control sera were included on each microtitre plate. The contents of all wells were then mixed thoroughly and left at room temperature. Reactions were recorded at three hours and again after further overnight incubation at room temperature using the criteria for agglutination, as described by the manufacturers. Those sera giving positive agglutination at titres of $1 / 40$ or greater were recorded as being positive for IgM rheumatoid factor.

\section{END POINT LASTER NEPHELOMETRIC ASSAY}

The Hyland PDQ nephelometer was used (Travenol Laboratories Ltd, Thetford, Norfolk, England). In this assay the patients' IgM rheumatoid factor reacts with human heat aggregated IgG supplied by the manufacturers (LAS-R rheumatoid factor antigen (human)). The resultant immune complexes scatter light from a laser beam in proportion to the amount of IgM rheumatoid factor present in the test sera. Sera were thawed from $-20^{\circ} \mathrm{C}$ at room temperature and then heated at $56^{\circ} \mathrm{C}$ for 30 minutes to inactivate complement.

Cuvettes prepared with filtered saline were filled with $100 \mu \mathrm{l}$ of patients' or control sera plus $200 \mu \mathrm{l}$ of the LAS-R antigen. Relative light scanner readings were taken according to the manufacturers'
Table 1 Non-rheumatoid arthropathies group

\begin{tabular}{|c|c|}
\hline Diagnosis & No $(\%)$ \\
\hline $\begin{array}{l}\text { Osteoarthritis } \\
\text { Psoriatic arthritis } \\
\text { Polymyalgia rheumatica } \\
\text { Paget's disease } \\
\text { Reiter's syndrome } \\
\text { Chronic gouty arthritis } \\
\text { Ankylosing spondylitis } \\
\text { Cervical spondylitis } \\
\text { Hypermobility } \\
\text { Soft tissue rheumatism }\end{array}$ & $\begin{aligned} 27 & (47) \\
11 & (19) \\
4 & (6 \cdot 9) \\
3 & (5 \cdot 2) \\
2 & (3 \cdot 4) \\
4 & (6 \cdot 9) \\
1 & (1 \cdot 7) \\
1 & (1 \cdot 7) \\
1 & (1 \cdot 7) \\
4 & (6 \cdot 9)\end{aligned}$ \\
\hline Total & $58(100)$ \\
\hline
\end{tabular}

instructions at 20 and 90 minutes for test and control cuvettes. Any sample giving a relative light scatter value greater than 10 at 20 minutes was considered to be positive. Any sample giving a negative result at 20 minutes and subsequently giving a relative light scatter value of three or more at 90 minutes was also considered to be positive. The delayed second reading was intended to take into account the slower rate of complex formation that may occur in weakly positive sera.

\section{STATISTICAL ANALYSIS}

Results obtained from the three assays were analysed by: two by two contingency analysis; the $\chi^{2}$ test with Yates' correction ${ }^{13}$; Yule's coefficient of colligation $^{14}$; and Cochran's test. ${ }^{15}$ The ages of patients in the groups with rheumatoid arthritis or non-rheumatoid arthropathies were analysed by quartile distribution and by the $\chi^{2}$ test with Yates' correction $^{13}$ and the median test. ${ }^{16}$

\section{Results}

Tables 1 to 5 show the results. There were no significant differences between the patients with rheumatoid arthritis and those with non-rheumatoid arthropathies in distribution of ages (table 2).

Table 2 Age distribution (years): analysis by quartiles

\begin{tabular}{lll}
\hline & $\begin{array}{l}\text { Rheumatoid } \\
\text { arthritis group }\end{array}$ & $\begin{array}{l}\text { Non-rheumatoid } \\
\text { arthropathies group }\end{array}$ \\
\hline Mean & $55 \cdot 8$ & 51 \\
Range & $26-76$ & $17-81$ \\
First quartile & 50 (at point 18) & 39 (at point 15) \\
Second quartile & 57 (at point 35) & 51 (at point 29.5) \\
Third quartile & 63 (at point 52) & 63 (at point 44) \\
Semi-interquartile range & $6 \cdot 5$ 12 \\
Total No in set & 69 & 58 \\
& & $\chi^{2}$ test with Yates' correction \\
Median test & \multicolumn{2}{c}{$\chi^{2}=2 \cdot 14$ (p > 0.1) } \\
\hline
\end{tabular}


Table 3 Difference in IgM rheumatoid factor detection between rheumatoid arthritis and non-rheumatoid arthropathies groups with three tests*

\begin{tabular}{|c|c|c|c|c|c|c|}
\hline & \multicolumn{2}{|l|}{ Latex fixation } & \multicolumn{2}{|c|}{ Haemagglutination } & \multicolumn{2}{|l|}{ Nephelometry } \\
\hline & $\begin{array}{l}\text { No } \\
\text { positive (\%) }\end{array}$ & No negative & $\begin{array}{l}\text { No } \\
\text { positive (\%) }\end{array}$ & No negative & $\begin{array}{l}\text { No } \\
\text { positive (\%) }\end{array}$ & $\begin{array}{l}\text { No } \\
\text { negative }\end{array}$ \\
\hline $\begin{array}{l}\text { Rheumatoid arthritis } \\
\text { Non-rheumatoid arthropathies } \\
\chi^{2} \\
\mathrm{p} \\
\mathrm{Y}\end{array}$ & $\begin{aligned} 52(75 \cdot 4) \\
6(10 \cdot 4) \\
51 \cdot 1 \dagger \\
<0.0005 \\
0.68\end{aligned}$ & $\begin{array}{l}17 \\
52\end{array}$ & $\begin{array}{l}51(73 \cdot 9) \\
5(8 \cdot 6) \\
54 \cdot 5 t \\
<0.0005 \\
0.69\end{array}$ & $\begin{array}{l}18 \\
53\end{array}$ & $\begin{array}{l}38(55 \cdot 1) \\
6(10 \cdot 4) \\
25.9 \dagger \\
<0.0005 \\
0.53\end{array}$ & $\begin{array}{l}31 \\
52\end{array}$ \\
\hline
\end{tabular}

$* 2 \times 2$ contingency table with $\chi^{2}$ analysis and Yule's coefficient of colligation (Y). $+\chi^{2}$ test.

Table 3 shows that in the group with rheumatoid arthritis $75.4 \%$ of sera were positive by latex fixation, $73.9 \%$ by haemagglutination, and $55.1 \%$ by nephelometry. In the group with non-rheumatoid arthropathies $10.4 \%$ of sera were positive by latex fixation, $8.6 \%$ by haemagglutination, and $10.4 \%$ by nephelometry. Table 3 also shows that the differences in the rates of positive results between these two groups were highly significant $(p<0.0005)$ for all three assays. The $\chi^{2}$ value for the nephelometric assay, however, was about half that for the latex fixation and haemagglutination assays; therefore Yule's coefficient of colligation was applied to the same data. In this statistical method the ability of the assay being analysed to discriminate between a positive and a negative result becomes more powerful the closer $Y$ approaches unity. The latex fixation and haemagglutination assays have almost identical $Y$ values, which are significantly greater than the $Y$ value $\overrightarrow{\vec{\omega}}$ obtained for the nephelometric assay. In table 4 the $\frac{5}{2}$ positive and negative results obtained with each assay? were compared with those obtained using the other $\overrightarrow{0}$ two assays with two by two contingency analysis. In iv the group with rheumatoid arthritis there was no significant difference in the number of positive results

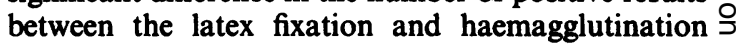
assays. Both latex fixation and haemagglutination, $\vec{T}$ however, produced a significantly higher number of $\mathbb{D}$ positive results than nephelometry $(p<0.025$ and $p$ 을 $<0.05$, respectively; see table 4). To confirm that the results obtained with nephelometry were significantly different from those obtained with the other two tests $\varnothing$ the same data were analysed by Cochran's test. Fo . both latex fixation and haemagglutination the differences between them and the nephelometric ass were highly significant $\left(\chi^{2}=24.4, p<0.0005\right)$. In the

Table 4 Difference between three tests used in detection of IgM rheumatoid factor in patients with rheumatoid arthritis or non-rheumatoid arthropathies

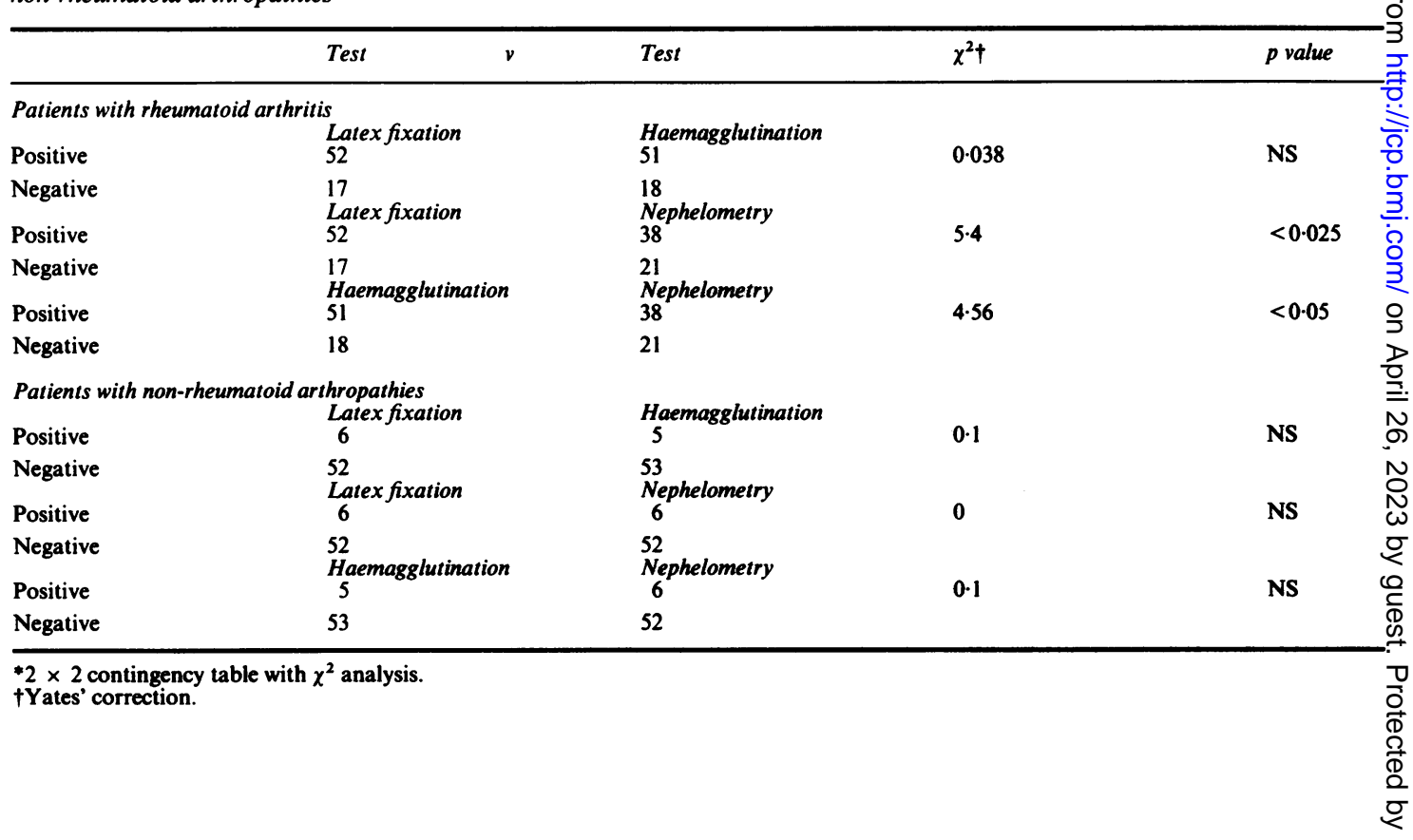


Table 5 Ratio of positive:negative IgM rheumatoid factor assays in patients with rheumatoid arthritis by age range

\begin{tabular}{llll}
\hline \multirow{4}{*}{ Test } & \multicolumn{3}{l}{ Age (years) } \\
\cline { 2 - 4 } & $0-49$ & $50-59$ & $60+$ \\
\hline Latex fixation & 1.13 & 2.83 & 5.2 \\
Haemogglutination & 1.43 & 2.29 & 4.17 \\
Nephelometry & 0.55 & 0.92 & 2.1 \\
Mean & 1.04 & 2.01 & 3.82 \\
\hline
\end{tabular}

group with non-rheumatoid arthropathies there were no significant differences when each test was compared with the other two in the same way.

Table 5 shows that in the group with rheumatoid arthritis positivity for IgM rheumatoid factor increased with age and that the lower rate of detection by the nephelopmetric assay persisted throughout the age groups. In the group with rheumatoid arthritis there were three discrepant results between the latex fixation and haemagglutination assays, and in all three nephelometric assay was negative. In the group with non-rheumatoid arthropathies only one patient gave a discrepant result between latex fixation and haemagglutination.

\section{Discussion}

Enthusiastic reports of the value of nephelometric assays of IgM rheumatoid factor have recently been published. ${ }^{9-12}$ It has been suggested that this technique has specificity and sensitivity equal to or greater than the established assays based on particle agglutination. The results obtained in this study do not confirm this. The latex fixation and haemagglutination assays had equivalent sensitivity and specificity, which were greater than those of the nephelometric assay. This was surprising and requires explanation. One explanation may be that this is the first study in which assays of IgM rheumatoid factor have been compared prospectively and blindly in patients who were defined strictly according to ARA clinical criteria alone. ${ }^{1}$ It is also the largest prospective study of this sort to have been done.

In a comparative study ${ }^{9}$ of 92 patients with a variety of joint disorders, 72 of whom had rheumatoid arthritis, nephelometry was found to be as accurate an assay of IgM rheumatoid factor as the differential agglutination test (DAT). In the group with rheumatoid arthritis, however, both assays had detection rates of $61 \%$, which is similar to the nephelometric rate in this report $(55.1 \%)$, but all are unacceptably low rates compared with a DAT detection rate of $77 \%$ obtained in one series of 1102 tests. ${ }^{17}$ In another study $^{10}$ assays of IgM rheumatoid factor by latex fixation and nephelometric techniques were com- pared in 100 consecutive patients admitted to a geriatric unit. Only three had rheumatoid arthritis - two with radiological lesions but no clinical activity. Eighty nine patients gave negative results by both assays, which suggests a high degree of concordance, but the authors concluded that the latex slide test had a $9 \%$ incidence of false positive results compared with a $2 \%$ incidence using nephelometry. When the results from our study are broken down into age groups and the ratio of positive:negative results is obtained, then the nephelometric assay consistently scores a much lower positive rate for all age groups, and in the patients over 60 years of age fails to achieve the ratio obtained by the latex fixation and haemagglutination assays in the patients aged 50 to 59 years. This lower sensitivity may explain why a lower false positive rate was obtained with a nephelometric assay in the study of geriatric patients. ${ }^{10}$ It is unlikely that the difference in the false positive rates between the latex fixation and nephelometric assays carried any statistical significance in that study.

Two further studies, both retrospective, concluded that the nephelometric assay was equal to other techniques. ${ }^{1112}$ In the first of these ${ }^{11}$ sera were assayed for IgM rheumatoid factor retrospectively from 30 patients with classic or definite rheumatoid arthritis and 23 healthy controls. Good correlation between a radioimmunoassay and a nephelometric assay was obtained $(r=0.97, p<0.001)$, but sensitivity and specificity were not reported. In the second study ${ }^{12}$ a rate nephelometric assay was compared with a latex fixation assay and an R-W assay in sera from 100 patients with rheumatoid arthritis, 70 with nonrheumatoid arthropathies, and 50 blood donors. Comparable sensitivities were obtained, although the nephelometric assay was less specific than the others. The detection rates were high (nephelometry $80 \%$, latex fixation $83 \%, \mathrm{R}-\mathrm{W} 75 \%$ ) in the group with rheumatoid arthritis compared with $70 \%$ for a latex fixation assay in a much larger study, (Lloyd KN, et al. Abstract, XIV International Congress of Rheumatology, San Francisco, 1981), and they suggest a bias in selection of sera in such a retrospective study.

Superficially, use of rate nephelometry seems to give greater sensitivity to the IgM rheumatoid factor assay than an end point technique, if the results of the study by Roberts-Thomson et $^{12}{ }^{12}$ are compared with those of Pritchard and Jobbins. ${ }^{9}$ It has been shown in another recent study, ${ }^{17}$ however, that rate nephelometry produces a detection rate in patients with rheumatoid arthritis in line with that found in our study. The $\mathbf{R}-\mathbf{W}$, latex fixation rate nephelometry and enzyme linked immunosorbant (ELISA) assays of IgM rheumatoid factor were compared in $\mathbf{4 8}$ patients with rheumatoid arthritis and 48 blood donors. In the group with rheumatoid arthritis the positive rates 
were $60 \%, 90 \%, 69 \%$, and $92 \%$, respectively. That study was not described as prospective or blind, or of patients selected by clinical criteria alone. Therefore the comparatively high latex fixation and ELISA results suggest that sera may have been preselected by another method or that only classic and no definite patients with rheumatoid arthritis were studied. The difference between the detection rate in the latex fixation assay and that of the nephelometric assay, however, was comparable to that reported here. Rate nephelometry does not consistently improve the sensitivity of the nephelometric assay.

Although the methodologies of latex fixation and nephelometry were comparable in all the studies reviewed, including the present study, the cellular agglutination assays were varied. It is unlikely that this variability of techniques explains the variable results in these studies, however, as the results obtained with diverse cellular agglutination techniques have been shown to be comparable in this study and in a previous study. ${ }^{10}$

In summary, it seems that there are sufficient grounds for not accepting either end point or rate laser nephelometry as equal to or better than any other technique used to detect serum IgM rheumatoid factor. This is particularly true in view of the results presented in this study, where the assays were used as screening tests to confirm clinical diagnoses based on ARA criteria. Nephelometric assays may have a place in quantitation of $\operatorname{IgM}$ rheumatoid factor in patients already known to be seropositive, ${ }^{1217}$ although the superior sensitivity of the ELISA method suggests that it may be preferable for quantitation. ${ }^{17}$

\section{References}

1 Ropes MW. Diagnostic criteria for rheumatoid arthritis 1958 revision. Ann Rheum Dis 1959;18:49-53.

2 Rose HM, Ragan C, Pearce D, Lipman MO . Differential agglutination of normal and sensitised sheep erythrocytes by sera of patients with rheumatoid arthritis. Proc Soc Exp Biol Med 1948;68:1-6.

3 Singer JM, Plotz CM. The latex fixation test. 1 Application to the serological diagnosis of rheumatoid arthritis. Am J Med 1956; 21:888-92.

4 Asuma T, Mizuoka K, Horikoshi A. Sensitised blood cell agglutination test for rheumatoid factor (RAHA test). Ryumachi 1973;12(4):330-6.

5 Waller M. Methods of measurement of rheumatoid factor. Ann NY Acad Sci 1969;168:15-20.

6 Zutshi DW, Reading CA, Epstein WV, Ansell BM, Holborrow EJ. F11 haemagglutination test for serum antigammaglobulin in arthritides sero-positive and sero-negative by other tests. Ann Rheum Dis 1969;28:289-99.

7 Deaton CD, Maxwell KV, Smith RS, Revelling RL. Use of laser nephelometry in the measurement of serum proteins. Clin Chem 1976;22:1465-71.

8 Finley PR, Hicks J, Williams RJ, Hinlicky J, Lichti DA. Rate nephelometric measurement of rheumatoid factor in serum Clin Chem 1979;25:1909-14.

9 Pritchard MH, Jobbins K. Nephelometry versus differential agglutination titre in the measurement of rheumatoid factor. $J$ Clin Pathol 1981;34:396-99.

10 Knight RK, Pritchard MH. Nephelometry compared with differential antibody titre in routine rheumatoid factor measurements. Ann Rheum Dis 1982;41:426-30.

11 Roberts-Thomson PJ, Wernick RM, Ziff M. Quantitation of rheumatoid factor by laser nephelometry. Rheumatology 1982;2:17-20.

12 Roberts-Thomson PJ, McEvoy R, Langhans T, Bradley J. Routine quantification of rheumatoid factor by rate nephelometry. Ann Rheum Dis 1985;44:379-83.

13 Edwards AL. Statistical methods. London: Holt, Rinehart and Winston, 1967.

14 Muircheartaigh C, Francis DP. Statistics-a dictionary of terms and ideas. London: Arrow Books, 1981.

15 Daniel WW. Applied non-parametric statistics. London: Houghton Mifflin, 1978.

16 Quirin WL. Probability and statistics. London: Harper and Row, 1978.

17 Bampton JLM, Cawston TE, Kyle MV, Hazleman HL. Measurement of rheumatoid factors by an enzyme-linked immunosorbant assay (ELISA) and comparison with other methods. Ann Rheum Dis 1985;44:13-9.

18 Finnie A, Mason M, Muir C. Evaluation of the TAHA test for rheumatoid factor. Med Lab Technol 1974;31:323-6.

Requests for reprints to: Dr AG Prentice, Consultant Haematologist, Derriford Hospital, Derriford Road, Plymouth PL6 8DH, England. 